\title{
The arthroscopic treatment of displaced tibial spine fractures in children and adolescents using Meniscus Arrows ${ }^{\circledR}$
}

\author{
Diederick B. Wouters • Joost S. de Graaf • \\ Patrick H. Hemmer · Johannes G. M. Burgerhof • \\ William L. M. Kramer
}

Received: 13 January 2010/ Accepted: 15 November 2010/Published online: 11 December 2010

(C) The Author(s) 2010. This article is published with open access at Springerlink.com

\begin{abstract}
Purpose This article summarises the results of a newly developed technique that utilises Meniscus Arrows ${ }^{\circledR}$ for the arthroscopic fixation of displaced tibial spine fractures in children and adolescents.

Method Twelve tibial spine fractures in the knees of eleven children between 6 and 15 years old, with an average age of 12 years, were arthroscopically fixed with Meniscus Arrows ${ }^{\circledR}$, after a reduction of their fractures. This was followed by 5 weeks immobilisation in a plaster of Paris. Postoperative follow-up included radiographs, Lachmann tests on all of the children's knees and KT-1000 tests of eight out of twelve of the children's knees. The postoperative follow-up time ranged from 3 to 10 years, with patients being seen for an average of 4 years.

Results All of the fractures consolidated uneventfully, and all of the patients returned unrestricted to their previous activity level. The Lachmann tests revealed no, or a
\end{abstract}

D. B. Wouters $(\bowtie)$

Department of General Surgery, Traumatology and Arthroscopic Surgery, TweeSteden Hospital, Dr. Deelenlaan 5,

5042 AD Tilburg, The Netherlands

e-mail: dwouters@tsz.nl

J. S. de Graaf · P. H. Hemmer

The Department of Surgery, Medical Centre Leeuwarden,

Henri Dunantweg 2, 8934 AD Leeuwarden, The Netherlands

J. G. M. Burgerhof

Department of Epidemiology, University Medical Centre

Groningen, Hanzeplein 1, 9713 GZ Groningen, The Netherlands

W. L. M. Kramer

The Department of Pediatric Traumatology, University Medical

Centre, Lundlaan 6, 3584 EA Utrecht, The Netherlands non-functional, laxity in any of the patients' knees. The KT-1000 tests showed a difference between the operated side, and non-operated side, of between $3 \mathrm{~mm}$ in the first knee operated on and an average of $1 \mathrm{~mm}$ in the remaining knees.

Conclusion The arthroscopic fixation of tibial spine fractures using Meniscus Arrows ${ }^{\circledR}$ showed that this minimally invasive procedure resulted in the uneventful consolidation of all twelve of the fractures, with excellent results, and without the need for a second, hardware removal, operation. Level of Evidence: Level IV

Keywords Arthroscopy · Tibial spine fracture · Meniscus Arrows · Internal fixation · Biodegradable

\section{Introduction}

Displaced fractures of the tibial spine, type 2 and 3 according to Meyers and Mc Keever, should be replaced and fixed [17-20]. This kind of fracture is most commonly found in adolescents and originates from the same trauma mechanism as the ACL rupture in adults [19, 22]. Screws, $\mathrm{K}$-wires, a cerclage of suture material or metal wire have been described as fixation devices [1-3, 8, 12, 15-17, 20]. To reduce the operation-related morbidity, an arthroscopic procedure is preferred $[1-3,5,6,8,11,14-16,19,20]$. However, if non-biodegradable devices are used, a second operation is often required to remove the hardware $[3,5,6$, $9,11]$. The use of biodegradable devices makes this removal operation unnecessary. In et al. [7] reported the application of biodegradable anchors, Perugia et al. [19] resorbable PDS sutures and recently Liljeros et. al. [13] the use of biodegradable nails, Smart Nails ${ }^{\circledR}$ (SNs) for this indication. 
The hold of Meniscus Arrows ${ }^{\circledR}$ (MAs) in bone is evaluated in a former study. The average pull-out force of one Meniscus Arrow ${ }^{\circledR}$ (MA) out of a human femur condyle is found to be $68 \mathrm{~N}$ and a bone block with three arrows $122 \mathrm{~N}$, according to in vitro extraction tests [23]. SNs need comparable pull-out forces or less [24]. Data of cerclages used for this indication are lacking in literature.

A second advantage is that the diameter of the MAs, $1.1 \mathrm{~mm}$ in diameter $(\varnothing)$, is less than half of the diameter of the smallest available cannulated screws $(2.4 \mathrm{~mm} \varnothing)$ and also thinner than the SNs with a $26 \%$ larger diameter of $1.5 \mathrm{~mm}$.

The purpose of this study is to evaluate and present the results of the use of MAs as fixation devices in the treatment of displaced tibial spine fractures of twelve knees in eleven children. This gives the advantage of an arthroscopic, one-stage operation and, due to their small diameter, also minimises the risk of fragmentation of the fragment.

\section{Materials and methods}

The study design is a prospective, consecutive and descriptive patient series of twelve knees of eleven patients: four boys and seven girls treated between 1999 and 2009.

Inclusion criteria were displaced tibial spine fractures type 2 and 3 according to Meyers and Mc Keever in skeletally immature patients. Their age varied between six and 15 years, with an average of 12 years.

\section{Arthroscopic technique}

The displaced tibial spine fractures were eleven times reduced using the MAs insertion device and, in one case, an anterior cruciate ligament-aiming device. Subsequently, arthroscopic fixation followed, using different numbers and lengths of MAs, depending on the size of the fragment and the distance to the growth plate.

The fixation procedure is as follows: first, reduction and temporary fixation with one Kirschner wire (K-wire, $1.0 \mathrm{~mm} \varnothing)$ under arthroscopic and fluoroscopic control
(Fig. 1). Subsequently, a second drill hole in the fragment is made through the shaft, inserted along the first $\mathrm{K}$-wire, with a second K-wire under fluoroscopic control, according to the desired length of the MA. Then, leaving the shaft exactly in place, the K-wire is exchanged by an MA, inserted by gentle hammering into the drill hole. Next, the shaft is placed over the first $\mathrm{K}$-wire, and this wire is replaced by another MA as well. This procedure is repeated as often as necessary to achieve a firm fixation of the fragment.

An arthroscopy cannula $(7 \mathrm{~mm} \varnothing)$, in length corrected by cutting off its end, can be used to facilitate the retropatellar passage and to protect the cartilage during the repeated insertion of the instruments.

Postoperatively, the knees were immobilised in a plaster of Paris splint for 2 weeks, followed by a circular plaster for 3 weeks.

During the first period, muscle setting exercises commenced; during the second period, touching the ground was allowed as well. After removal of the plaster, all patients were loading their leg progressively and were encouraged to perform closed-chain and propriocepsisrestoring exercises.

During the control visits on outpatient base radiographs, Lachmann-Anterior Drawer Sign (ADS)—and KT-1000 tests, where possible, were performed.

\section{Results}

Consolidation of the fractures occurred in all patients in the initial position. In general, 4 weeks after plaster removal a full range of motion was achieved.

A mild anterior-posterior (a-p) laxity was found during Lachmann and ADS tests in two out of the twelve knees. Nevertheless, none of the patients complained of giving away sensations during activities, and they returned to their previous activity level. The KT-1000 tests showed a maximum difference of laxity between both knees of $3 \mathrm{~mm}$ in the first patient, $2 \mathrm{~mm}$ in the second patient, and the next patients showed a variation of between $1.5 \mathrm{~mm}$ and $-0.1 \mathrm{~mm}$ (the operated side was $0.1 \mathrm{~mm}$ less lax). One patient sustained, after radiological tests confirmed the
Fig. 1 a The displaced fracture, b reposition and primary fixation with a K-wire
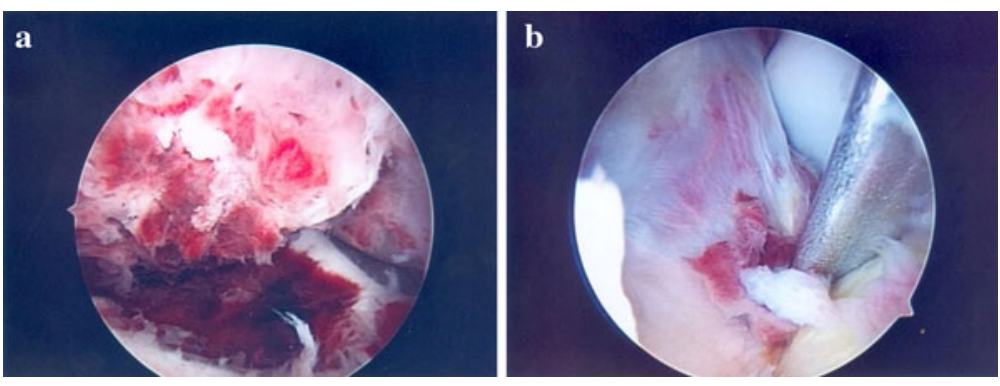
consolidation of the fracture; a re-fracture 2 years later, while playing soccer on the previous competition level again since 15 months. A re-operation was performed, using five MAs with an undisturbed course postoperatively, and again, consolidation of this fracture followed without sequelae 5 years afterwards.

\section{Discussion}

The most important finding of the present study was the uneventful consolidation of all fragments in its initial position after one, arthroscopical, procedure, a minimal, non-functional a-p laxity and the unrestricted return of all patients to their previous activity level without any pain.

No operation-related complications or growth disturbances occurred.

The first two patients showed the largest post-operative KT-1000 value differences, $3 \mathrm{~mm}$ and $2 \mathrm{~mm}$, respectively, compared to the non-operated side. However, they did not mention restrictions in their daily activities and previous sport activities, i.e. gymnastics and soccer. In the next ten patients, the differences varied between $1.5 \mathrm{~mm}$ and $-0.1 \mathrm{~mm}$, due to the learning curve and the awareness of the necessity of precise reduction of the fragment. This need for proper reduction is also recently stressed in the paper of Tudisco et al. [20].

A discretely increased a-p laxity (average $1 \mathrm{~mm}$ ) is noted in this series without functional complaints. This is also described by Kocher et al. [9] and Tudisco et al. [20] and not resulting in their series to functional complaints as well. Although larger laxities, like $6 \mathrm{~mm}$, seem to be tolerated well and do not result in a clinical or subjective feeling of instability [19], we agree with Tudisco et al. [20] that aiming at normal values should be the ultimate goal of the surgical procedure. All patients in this series reported during the last visit the return to their previous level of activities and sports, soccer, hockey and gymnastics without pain or restrictions. Although not specified in KOOS, according to the eight instrumented tests (KT-1000), the outcome would be seven times normal and once nearly normal according to the IKDC examination form 1999.

In general, when metallic fixation devices like screws, $\mathrm{K}$-wires or cerclage wire are used in the treatment of displaced tibial spine fractures, removal is required during a second procedure $[3,5,6,9,11]$, which is in contrast to the single surgery using MAs.

A second advantage of the MAs is the small diameter of $1.1 \mathrm{~mm}$. The risk of fragment splitting, compared to the application of the more bulky cannulated screws of $2.4 \mathrm{~mm}$ or more, is minimised, and even fragments, too small to be fixed with screws, like in very young patients, can be fixed with MAs. Another advantage of the small diameter is the possibility of using more devices at the same time, leading to less damage of the fragment and a better distribution of the compressive forces, as Weckström et al. stated [21].

The proper length can be measured accurately under fluoroscopy, avoiding damage to the growth plate, especially relevant in very young children under the age of 10 years old. Hirschmann et al. [5] describe a physeal sparing arthroscopic technique as well, using non-resorbable sutures and an extra-articular screw in six patients, but not without drawbacks. Two times this screw had to be removed. One patient was not pain-free at the last visit. A second disadvantage in our view is that the suture and screw complex is not producing direct compression on the fragment in its bed, which could be disadvantageous as well.

The arthroscopic insertion of anchors and knotting the threads [7] appear to be more complex to perform than the simple drilling and insertion of the nail-like devices like SNs and MAs. The SNs, already successfully applied for the fixation of tibial spine fractures and osteochondral fractures, on the contrary, have the disadvantage of a substantial, 26\% larger diameter of $1.5 \mathrm{~mm}$ than the MAs $[4,13,21,24]$.

The number of reports of chondral damage and implant failure while using MAs in meniscal surgery is limited to only a few case reports, like the one of Kurzweil et al. [10], despite their frequent and worldwide numerous application in orthopaedic procedures. From 2006, the heads of the MAs are rounded off and smoothened and being inserted in the notch, they will not be in contact with cartilage anyway. In the present series, no implant failure was found.

This series is of limited size, i.e. 12 knees, restricting the statistical power of significance. However, because of the infrequent occurrence of this fracture, the numbers in other series are restricted as well, ranging from 5 [17] to 16 [18]. A large multicentre study will be needed to provide enough data to compare the different therapies with sufficient statistical power.

\section{Conclusion}

Arthroscopic fixation of tibial spine fractures using Meniscus Arrows ${ }^{\circledR}$ is a minimal invasive procedure, which resulted in uneventful consolidation of all twelve fractures in this patient series with excellent results and without the need for a second, hardware removal, operation. The smaller diameter, compared to the Smart Nail ${ }^{\circledR}$, makes the Meniscus Arrow ${ }^{\circledR}$ arguably the more preferred device for this indication. Accurate reduction before fixation can improve the results. 
Acknowledgments We would like to express our gratitude to Miss P.B.S. Wouters and Mr. P.E. Walsh for their linguistic revision of this manuscript.

Conflict of interest The authors declare that they have no conflict of interest.

Open Access This article is distributed under the terms of the Creative Commons Attribution Noncommercial License which permits any noncommercial use, distribution, and reproduction in any medium, provided the original author(s) and source are credited.

\section{References}

1. Bale RS, Banks AJ (1995) Arthroscopically guided Kirschner wire fixation for fractures of the intercondylar eminence of the tibia. J R Coll Surg Edinb 40:260-262

2. Berg EE (1995) Pediatric tibial eminence fractures: arthroscopic cannulated screw fixation. Arthroscopy 11:328-331

3. Binnet MS, Gürkan I, Yilmaz C, Karakas A, Çetin C (2001) Arthroscopic fixation of intercondylar eminence fractures using a 4-portal technique. Arthroscopy 17:450-460

4. Dines JS, Fealy S, Potter HG, Warren RF (2008) Outcomes of osteochondral lesions of the knee repaired with a bioabsorbable device. Arthroscopy 24:62-68

5. Hirschmann MT, Mayer RR, Kentsch A, Friederich NF (2009) Physeal sparing arthroscopic fixation of displaced tibial eminence fractures: a new surgical technique. Knee Surg Sports Traumatol Arthrosc 17:741-747

6. Hunter RE, Willis JA (2004) Arthroscopic fixation of avulsion fractures of the tibial eminence: technique and outcome. Arthroscopy 20:113-121

7. In Y, Kim JM, Woo YK, Choi CW, Kim MW (2008) Arthroscopic fixation of anterior cruciate ligament avulsion fractures using biodegradable suture anchors. Knee Surg Sports Traumatol Arthrosc 16:286-289

8. Jung YB, Yum JK, Koo BH (1999) A new method for arthroscopic treatment of tibial eminence fractures with eyed steinman pins. Arthroscopy 15:672-675

9. Kocher MS, Foreman ES, Micheli LJ (2003) Laxity and functional outcome after arthroscopic reduction and internal fixation of displaced tibial spine fractures in children. Arthroscopy 19:1085-1090

10. Kurzweil PR, Tifford CD, Ignacio EM (2005) Unsatisfactory clinical results of meniscal repair using the meniscus arrow. Arthroscopy 21:905
11. Lais E, Hertel P, Goudarzi AM (1987) Die arthroscopische versorgung der dislozierten ausrisse der eminentia intercondylica bei kinder und jugendlichen. Unfallchirurg 90:471-477

12. Lee YH, Chin LS, Wang NH et al (1996) Anterior tibial spine fracture in children: follow-up evaluation by biomechanical studies. Chung Hua I Hsueh Tsa Chih 58:183-189

13. Liljeros K, Werner P, Janarv PM (2009) Arthroscopic fixation of anterior tibial spine fractures with bioabsorbable nails in skeletally immature patients. Am J Sports Med 37:923-928

14. Lubowitz JH, Grauer JD (1993) Arthroscopic treatment of anterior cruciate ligament avulsion. Clin Orthop Relat Res 294:242-246

15. Mah JY, Adili A, Otsuka NY, Ogilvie R (1998) Follow-up study of arthroscopic reduction and fixation of type III tibial eminence fractures. J Pediatr Orthop 18:475-477

16. Mc Lennan JG (1982) The role of arthroscopic surgery in the treatment of fractures of the intercondylar eminence of the tibia. J Bone Joint Surg Br 64:477-480

17. Meyers MH, Mc Keever FM (1959) Fracture of the intercondylar eminence of the tibia. J Bone Joint Surg 41A:209-222

18. Meyers MH, Mc Keever FM (1970) Fracture of the intercondylar eminence of the tibia. J Bone Joint Surg 52A:1677-1684

19. Perugia D, Basiglini L, Vadala A, Feretti A (2009) Clinical and radiological results of arthroscopically treated tibial spine fractures in childhood. Int Orthop 33:243-248

20. Tudisco C, Giovarruscio R, Febo A, Savarese E, Bisicchia S (2010) Intercondylar eminence avulsion fracture in children: long-term follow-up of 14 cases at the end of skeletal growth. J Pediatr Orthop (B) 19:403-408

21. Weckström M, Parviainen M, Kiuru MJ, Mattila VM, Pihlajamäki HK (2007) Comparison of bioabsorbable pins and nails in the fixation of adult osteochondritis dissecans fragments of the knee: an outcome of 30 knees. Am J Sports Med 35:1467-1477

22. Woo SL-Y, Hollis JM, Adams DJ (1991) Tensile properties of the human femur-anterior cruciate ligament-tibia complex: the effects of specimen age and orientation. Am J Sports Med 19:217-225

23. Wouters DB, Bos RRM, Mouton LJ, van Horn JR (2004) The meniscus arrow or metal screw for treatment of osteochondritis dissecans? in vitro comparison of their effectiveness. Knee Surg Sports Traumatol Arthrosc 12:52-57

24. Wouters DB, Burgerhof JGM, de Hosson JTM, Bos RRM (2010) Fixation of osteochondral fragments in the human knee using Meniscus Arrows ${ }^{\circledR}$. Knee Surg Sports Traumatol Arthrosc doi: 10.1007/s00167-010-1158-5 